\title{
OS (DES)CAMINHOS DA GESTÃO DEMOCRÁTICA DA CIDADE NAS OPERAÇÕES URBANAS CONSORCIADAS: O CASO BELORIZONTINO
}

\section{THE (DIS) WAYS OF THE DEMOCRATIC MANAGEMENT OF THE CITY IN THE INTERCROPPED URBAN OPERATIONS: THE CASE OF BELO HORIZONTE CITY}

\author{
Reginaldo Magalhães de Almeida ${ }^{1}$
}

\section{Resumo}

O presente artigo busca analisar a atuação do Ministério Público Estadual e do Poder Público Municipal na fiscalização e garantia da gestão democrática da cidade, assegurada pelo Estatuto da Cidade, no projeto de lei da Operação Urbana Consorciada Nova BH, que surgiu em 2013, e passou a ser denominado Operação Urbana Consorciada Antônio Carlos/Pedro I e Leste/Oeste em 2014. Tal projeto objetiva implementar intervenções urbanas com participação da iniciativa privada no município de Belo Horizonte. Através da união de pesquisadores das áreas da Arquitetura/Urbanismo e do Direito, foram realizados estudos em arquivos da Prefeitura Municipal de Belo Horizonte, do Ministério Público Estadual, além de livros, artigos e jornais, que serviram para coleta de dados e afirmações de autores conceituados no tema. O estudo também se baseia no Estatuto da Cidade e na Constituição Federal. Destaca-se, ao final, a deficiência da Administração Pública quanto à gestão democrática, entendendo-se que para a efetiva participação pública é necessário dar maior abertura à população nas decisões administrativas. Por outro lado, ressalta-se a atuação fiscalizadora do Ministério Público Estadual na garantia da gestão democrática da cidade. O artigo propicia a entrada de novos estudos que visam alternativas de promover a democracia participativa no planejamento e gestão das cidades, visto que a participação pública democrática é, de fato, essencial para o planejamento urbano.

Palavras-chave: Gestão Democrática da Cidade; Operação Urbana Consorciada; Prefeitura Municipal; Ministério Público Estadual.

\begin{abstract}
This article aims to analyze the performance of the State Public Ministry and the Municipal Public Power in the supervision and guarantee of the democratic management of the city, as guaranteed by the City Statute Law, in the bill for the "New BH Consorted Urban Operation", which appeared in 2013, to be called "Antônio Carlos /Pedro $1^{\circ}$ and East/West Consorted Urban Operation" in 2014. This project aims to implement urban interventions with private participation in the municipality of Belo Horizonte. Through the union of researchers in the areas of Architecture/Urbanism and Law, studies were carried out in the Belo Horizonte City Hall and the State Brazilian Government Agency for Law Enforcement's archives, as well as books, articles and newspapers, which served to collect data and authors' statements conceptualized in the theme. The study is also based on the City Statute Law and Federal Constitution. At the end stands out the deficiency of the Public Administration regarding democratic management, understanding that for the effective public participation it is necessary to give greater openness to the population in administrative decisions. On the other

\footnotetext{
${ }^{1}$ Doutorado em Arquitetura e Urbanismo pela Escola de Arquitetura da Universidade Federal de Minas Gerais (2014). Professor do Curso de Arquitetura da Universidade FUMEC - disciplinas de Planejamento Urbano, Projeto de Urbanismo e Mobilidade Urbana -, analista ambiental da Prefeitura Municipal de Belo Horizonte e consultor urbanístico e ambiental de Administrações Municipais. E-mail: ralmeida@fumec.br
} 
hand, it is important to point out that the State Brazilian Government Agency for Law Enforcement supervises the democratic management of the city. The article allows the entry of new studies that aim at alternatives to promote participatory democracy in the planning and management of cities, since the democratic public participation is essential for urban planning.

Keywords: Democratic Management of the City; Consorted Urban Operation; City Hall; State Brazilian Government Agency for Law Enforcement.

\section{INTRODUÇÃO}

A Lei 10.257/2001, conhecida como Estatuto da Cidade, é considerada um marco para o direito urbanístico brasileiro, na medida em que tornou obrigatório o cumprimento de diretrizes gerais da política urbana pelas três esferas do Poder Público. Com o intuito de planejar e controlar a gestão do solo urbano nas grandes e médias cidades no Brasil, dentre outros instrumentos de política urbana, instituiu a Operação Urbana Consorciada, que se caracteriza por um conjunto de intervenções urbanísticas e estruturais na cidade, coordenadas pelo Poder Público Municipal.

Duas instituições públicas são fundamentais no processo de implantação das Operações Urbanas Consorciadas, principalmente com relação à diretriz constitucional da gestão democrática, quais sejam, o Poder Público Municipal e o Ministério Público Estadual. Referidos órgãos públicos têm importante papel, na medida que cabe a eles zelar pelo efetivo cumprimento de tal diretriz constitucional, garantindo que a sociedade tenha informações claras sobre as Operações Urbanas Consorciadas, de modo que os cidadãos participem de forma ativa e real dos debates acerca da viabilidade e dos reflexos dos planos, programas e projetos urbanísticos.

Em Belo Horizonte, capital de Minas Gerais, a Operação Urbana Consorciada vem sendo utilizada desde 1996, ano no qual foi aprovado o primeiro Plano Diretor municipal da cidade (Lei n 7.165/96). A partir de então, foram implantadas e implementadas várias Operações Urbanas na cidade, que viabilizaram grandes empreendimentos imobiliários, regularização fundiária, construção de equipamentos públicos, reabilitação de áreas urbanas, preservação do patrimônio cultural edificado, dentre outros.

O objetivo deste artigo é analisar a atuação do Poder Público Municipal e do Ministério Público Estadual na garantia da gestão democrática da cidade, durante o processo de 
implantação do instrumento urbanístico jurídico das Operações Urbanas Consorciadas em Belo Horizonte.

Pretende-se descortinar se o Poder Público Municipal observou, quando da criação da lei específica referente à operação urbana, a diretriz constitucional da gestão democrática. Pretende-se também analisar a importância dos órgãos fiscalizadores, como o Ministério Público Estadual, na garantia da observância dos preceitos legais, de modo a assegurar a plena realização da gestão democrática, de cumprimento obrigatório assegurado pelo Estatuto da Cidade, ou seja, a garantia da participação da população na gestão municipal através de debates, audiências, consultas públicas, iniciativa popular de projetos de lei e de planos, programas e projetos de desenvolvimento urbano, bem como pela constituição de órgãos colegiados de política urbana e conferências. Desse modo, serão analisadas as deficiências da Administração Pública em estimular a gestão democrática, o que obsta a utilização do espaço de forma plena, impedindo que o cidadão desenvolva plenamente suas potencialidades.

Como estudo de caso, será utilizada a Operação Urbana Consorciada Nova BH, iniciada em 2013 e que, em 2014, passou a chamar-se Antônio Carlos/Pedro I e Leste/Oeste. Tal Operação Urbana envolve importantes vias de ligação regional da cidade e diversos bairros, totalizando uma área de influência direta de aproximadamente $9 \%$ da extensão territorial de Belo Horizonte (PBH,2016).

Os estudos para a realização deste artigo foram baseados em ampla pesquisa e análise documental, fundamentadas nos documentos arquivados pela Prefeitura de Belo Horizonte (PBH) e pelo Ministério Público Estadual (Coordenação de Urbanismo e Meio Ambiente) e que estão disponíveis ao acesso público. A análise envolveu também pesquisa em jornais, livros nos campos do Direito, da Arquitetura e do Urbanismo, reportagens, teses e dissertações.

Os dados e as análises apresentados aqui fazem parte de uma pesquisa iniciada em 2015, denominada "Possibilidades do uso das Operações Urbanas Consorciadas como instrumento de regularização urbanística: o caso de Belo Horizonte". Esta pesquisa objetiva, aproximar os campos de conhecimento da Arquitetura e do Direito, através do estudo das Operações Urbanas Consorciadas aprovadas em Belo Horizonte, desde 1996. A pesquisa conta com o apoio e o financiamento da Universidade FUMEC (ProPic/FUMEC/2016/2017) e da FUNADESP, sendo o grupo de pesquisadores formado por professores e alunos dos cursos de Arquitetura e Urbanismo e do Direito. 


\section{AS COMPETÊNCIAS URBANÍSTICAS}

A Constituição Federal de 1988 (BRASIL, 1988) reparte a competência urbanística para legislar entre os três entes federativos, competindo, assim, à União, aos Estados e aos Municípios criarem normas jurídicas urbanísticas (artigos 21, 24, 30 e 182, da Constituição Federal).

A partir da análise do texto constitucional, depreende-se que a competência do ente federativo federal se atém à elaboração de normas gerais sobre política urbana. Aos Estados foi outorgada a competência para legislar sobre matéria urbanística de forma suplementar e complementar. Lado outro, o Poder Público Municipal é o responsável pelo desenvolvimento urbano local.

Daniela Campos Libório Di Sarno (2001: 65) define a competência urbanística do Poder Público Municipal nos seguintes dizeres:

Na verdade, a instância local é que tem a competência material e legislativa para realizar a política urbana, conforme determina o art. 182 da Carta Magna. Significa dizer que o Poder Público Municipal tem um papel de grande importância (insubstituível até) na realização e concretização da organização e adequação do espaço urbano dentro dos princípios e diretrizes que tragam um desenvolvimento equilibrado e saudável para a sua população.

Assim, muito embora a atuação mais concreta e perceptível na prática seja realizada pela municipalidade, posto que esta exerce o papel de executora da política de desenvolvimento urbano, verifica-se que a função de legislar sobre a atividade urbanística compete às três esferas do Poder Público, de forma concorrente, cabendo-lhes definir procedimentos e normas acerca do regime jurídico da propriedade urbana. O papel do Poder Público Municipal, no que se refere à matéria urbanística, encontra previsão constitucional no artigo 30, incisos I, II e VIII, bem como, no artigo 182 (BRASIL, 1988).

Os Municípios possuem atuação direta e perceptível em assuntos de interesse local, promovendo adequadamente a ordenação do território, através do planejamento e controle do uso, do parcelamento e da ocupação do solo urbano. Tal atuação é feita fundamentalmente através de um instrumento básico de política de desenvolvimento e de expansão urbana, denominado de Plano Diretor.

Maurício Balesdent Barreira (1998) discorre sobre o papel do Município e do Plano Diretor da seguinte forma: 
Ora, é fácil perceber que a ordenação da cidade através de normas urbanísticas é assunto predominantemente local, e tal ideia se reforça-se ainda mais diante da explicitação da natureza do Plano Diretor, verdadeiro instrumento de planejamento estratégico do próprio Município, que, aplicado por sua legislação correlata - Lei do Uso, Ocupação e Parcelamento do Solo, Código de Obras e Código de Posturas - deve conter diretrizes das mais diversas, desde as relacionadas às condições de acesso dos cidadãos aos seus direitos sociais e fundamentais, como emprego, habitação e serviços, passando pela proteção ao meio ambiente e patrimônio natural e cultural, até aquelas que digam respeito ao perfil econômico do Município, entre outras (1998: 21).

Assim, compete ao Município planejar e gerir a cidade através de uma política urbana, buscando atender a função social da propriedade e o bem-estar de seus habitantes. Tal planejamento, que incluirá os critérios de utilização do solo, será estabelecido no Plano Diretor de cada cidade, que deverá ser aprovado pela Câmara Municipal (artigo 182, da Constituição Federal de 1988).

O Poder Público, mormente o municipal, deve, visando à consecução de seu papel urbanístico, valer-se dos instrumentos colocados à sua disposição e elencados exemplificativamente no art. 40 do Estatuto da Cidade. Como exemplo desses instrumentos de política urbana, merece destaque o instrumento urbanístico jurídico das Operações Urbanas Consorciadas.

Paulo José Villela Lomar (2006: 251), afirma que:

Esta orientação mais recente expressa certa descrença quanto à eficácia dos instrumentos apenas normativos de planejamento e se apresenta como estimuladora da adoção de uma modalidade de planejamento estratégico mais interventiva sobre a realidade urbana, mediada por ampla negociação entre os diversos agentes públicos, empreendedores e a sociedade civil.

Conclui-se, portanto, que promover o planejamento do uso do solo urbano deixou de ser uma mera faculdade do Município, posto que, constitui uma previsão constitucional. Por meio desse planejamento, o Poder Público Municipal pode estabelecer os objetivos e as estratégias definidoras do processo de utilização do solo urbano (SILVA, 2000).

Lado outro, contudo, e não menos importante, está o dever de implementação e fiscalização da legislação urbanística pelo Município, isto é, deve o Poder Público buscar efetivar o que os instrumentos legais consubstanciam e materializam, de modo a realmente alcançar os objetivos previstos na legislação. Dessa forma, a partir da implementação das normas, os efeitos almejados e previstos serão alcançados e sentidos pela população local, posto que, seus 
interesses reais foram perseguidos e contemplados em planejamentos correspondentes aos anseios da realidade urbana.

Impende destacar, ainda, que, com o advento da Constituição da República de 1988, coube ao Ministério Público o papel de defesa da ordem jurídica, do regime democrático e dos interesses sociais e individuais indisponíveis, conforme dispõe o artigo 127 do texto constitucional. Coube ao Ministério Público, portanto, o papel de zelar pelos rumos da sociedade, cumprindo sua função de exercer o controle externo do Poder Público.

Segundo Ximena Cardoso Ferreira (2017), em artigo sobre a atuação do Ministério Público na implementação de políticas públicas, o Ministério Público, como instituição autônoma e independente que é, detém liberdade de atuação, a qual é fundamental para se evitar ameaças e danos à coletividade.

\section{A OPERAÇÃO URBANA CONSORCIADA E A GESTÃO DEMOCRÁTICA DA CIDADE}

\section{A Operação Urbana Consorciada}

Em 2001, o Estatuto da Cidade, Lei Federal n 10.257, definiu Operação Urbana Consorciada como o conjunto de intervenções e medidas coordenadas pelo Poder Público Municipal, que conta com a participação dos proprietários, moradores, usuários permanentes e investidores privados, com o objetivo de alcançar em uma área “(...) transformações urbanísticas estruturais, melhorias sociais e a valorização ambiental” (BRASIL, 2001: 249).

Inicialmente, quanto à compreensão do alcance dos objetivos deste instituto jurídico, surge o questionamento acerca de ser indispensável a persecução cumulativa destes três objetivos simultaneamente ou se bastariam melhorias sociais ou a valorização ambiental, sem a pretensão da realização de transformações estruturais. (BRASIL, 2001: 249)

Daniela Abritta Cota aponta que a operação urbana foi idealizada para alcançar duas finalidades: primeiramente, "viabilizar interesses redistributivistas, ao propor uma nova lógica de participação da iniciativa privada na produção do espaço [...], bem como renovar as qualidades espaciais de determinadas áreas" (2011:40).

Outrossim, da definição de Operação Urbana trazida pelo art. 32, § 1ำ, do Estatuto da Cidade (BRASIL, 2001), extrai-se que a participação de todos os agentes envolvidos é de extrema importância para a aplicação do instrumento, não sendo restrita a participação apenas aos proprietários de imóveis situados nas áreas da operação, incluindo-se também os usuários permanentes (comerciantes que atuam na área, por exemplo) e investidores privados, além dos 
demais habitantes e usuários da urbe, posto que uma das diretrizes fundamentais do Estatuto da Cidade é a gestão democrática da cidade. (LOMAR, 2006).

Paulo José Villela Lomar (2006) assim concluiu:

A operação urbana consorciada pressupõe, portanto, processo especializado de gestão permanente de sua implementação, com observância da diretriz de gestão democrática, mediante ampla informação e participação da sociedade civil em todas as suas fases, no qual múltiplas e combinadas formas de intervenção são possíveis, total ou parcialmente, tudo dependendo de sua adequação aos aspectos peculiares e singulares de cada uma e de sua capacidade de mobilização de proprietários e empreendedores privados, sem prejuízo da coordenação pelo Poder Público Municipal, a fim de que o interesse público seja efetivamente concretizado (LOMAR, 2006: 288).

Para Maria Paula Dallari Bucci (2006), na garantia de compatibilização dos interesses dos agentes públicos e privados, os incisos XXXIII e XXXIV do art. 5ํ, assim como, o art. 37, caput, §§ 1ㅇ e 3ำ, ambos da Constituição Federal de 1988, asseguram o direito fundamental de permissão e facilitação do acesso às informações, estudos, planos, programas, projetos e outros documentos pertinentes, a quem tenha interesse em seu conhecimento.

Assim, o Poder Público Municipal, sem se despir do exercício e das responsabilidades de sua condição de autoridade pública, deverá promover e coordenar reuniões informativas com diferentes grupos sociais, auscultando suas críticas, indagações, sugestões e anseios, bem como, incorporando ao plano o que considere compatível com os objetivos propostos, de forma a construir um projeto com efetiva participação popular. A fim de assegurar o atendimento a tais finalidades, poderão ser realizadas audiências públicas, pesquisas de opinião, debates, consultas públicas, reuniões e assembleias plenárias, dentre outros meios existentes ou a serem criados, conforme dispõe o art. 43 do Estatuto da Cidade. Muito embora não haja meios de se obrigar a participação popular, o Poder Público não pode deixar de oferecer as oportunidades de participação, procedendo à ampla divulgação dos seus estudos e planos. Segundo LOMAR (2006: 253):

Esta exigência decorre, por um lado, do fato de a Constituição Brasileira ter instituído a democracia representativa e participativa e adotado a cidadania como um dos fundamentos do Estado Democrático de Direito. Paralelamente, o texto constitucional determinou, no inciso X do art. 29, que o Município assegure a cooperação das associações representativas dos diferentes grupos sociais no planejamento municipal.

O cumprimento das diretrizes de gestão pública democrática da cidade é obrigatório e de tal ordem, que, quando descumpridas, implicará na prática de impropriedade administrativa, com intervenção do Ministério Público - situação enfatizada no episódio da Operação Urbana 
Consorciada Antônio Carlos/Pedro I e Leste/Oeste, em Belo Horizonte, a ser tratada neste artigo.

Deve-se ressaltar, ainda, conforme dispõe o inciso III do art. 3o da Constituição Federal (1988), que o interesse público aplicado na operação urbana entende como fundamental a erradicação da pobreza e da marginalização, a redução das desigualdades regionais e sociais. Entretanto verifica-se, segundo Cota, (2011: 316) que:

Elas representam, assim, uma (re) atualização da possibilidade de geração de rendas fundiárias mediada pelo Estado: os direitos de construir envolvidos na aplicação do instrumento permite desvinculá-los do solo propriamente dito, evolvendo-os em um circuito onde o que se negocia é a virtualidade da capitalização da renda fundiária. Com isso, ao invés de ter a função principal de extração e redistribuição de valorizações imobiliárias decorrentes da atuação pública no espaço urbano, na prática, as operações urbanas em Belo Horizonte acabam viabilizando formas renovadas de capitalização e apropriação dessas valorizações por interesses particulares (proprietários de terrenos urbanos ou interessados incorporadores imobiliários).

Segundo Mariana Fix, no livro "Parceiros da Exclusão: duas histórias da construção de uma "nova cidade" em São Paulo: Faria Lima e Água Espraiada" (2001), o setor privado entra com forte participação nas intervenções urbanas, mas para benefício próprio, gerando fortes problemas sociais com desapropriações de grandes áreas sem o devido suporte. São planos que visam um lado da situação.

Os investimentos privados existem, mas não excluem a participação pública, que atua nos investimentos iniciais do empreendimento, com obras que sejam capazes de atrair a iniciativa privada, essencial para a Operação. "O Estado transforma-se, assim, no principal "sócio" da iniciativa privada na renovação urbana de algumas áreas, funcionando como um grande empreendedor imobiliário" (FIX, 2001: 117). Assim, são altos os riscos de prejuízo para o Estado e, consequentemente, para os cidadãos, assim como as possibilidades de lucro são ainda maiores para o setor privado.

Ainda em análise sobre a Operação Urbana, Cota (2011) afirma haver falhas de tal instrumento no Estatuto da Cidade e no Plano Diretor, posto que os artigos que o definem contém "imprecisões quanto aos limites de aplicação do instrumento, apresentando diretrizes genéricas e muito flexíveis que, apesar de nortearem sua aplicação, permitem que tudo possa se encaixar nas intervenções caracterizadas como Operações Urbanas (...)" (COTA, 2011: 312). Podendo, dessa forma, ser alvo de interesses particulares e/ou privados. 


\section{Gestão democrática da cidade}

A democracia participativa baseia-se na abertura do Estado a uma participação popular maior do que a admitida no sistema da democracia puramente representativa. Para tanto, a democracia participativa conta com os instrumentos institucionais até certo ponto novos, tais como a iniciativa popular de leis e o referendo, que importam na modificação do modo de atuação de todos os poderes estatais e na alteração do relacionamento Estado-sociedade. (PEREZ, 2004: 32)

O artigo 29, XII, da Constituição Federal (1988), ao tratar das normas básicas de organização dos municípios, prevê a cooperação de associações representativas no planejamento municipal, direcionando de forma genérica a adoção de institutos da participação popular pela Administração Pública. Impende ressaltar, ainda, que a Emenda Constitucional no 19, de 1998, que modificou e dispôs sobre princípios e normas da Administração Pública, introduziu no artigo 37, do texto constitucional, o § 3 ㅇ:

§3o A Lei disciplinará as formas de participação do usuário na administração pública direta e indireta, regulando especialmente:

I - as reclamações relativas à prestação dos serviços públicos em geral, asseguradas a manutenção de serviço de atendimento ao usuário e a avaliação periódica, externa e interna da qualidade dos serviços;

II - o acesso dos usuários a registros administrativos e a informações sobre atos do governo, observando o disposto no art. 5, X e XXXIII;

III - a disciplina da representação contra o exercício negligente ou abusivo do cargo, emprego ou função na administração pública. (Redação dada pela Emenda Constitucional no19, de 1998).

Portanto, a Emenda Constitucional no 19 acabou dando maior destaque ao que se refere à participação popular. Para Perez (2004), embora já houvesse referências à participação popular como instrumentos de regularização, se fez necessária, para sua efetivação, a inserção da participação nas disposições gerais da Administração Pública, no artigo 37 da Constituição Federal de 1988.

Ainda segundo Perez (2004), as atividades atribuídas à Administração Pública, citadas na Constituição sobre funções sociais, são para garantir igualdade de direitos a todos os setores sociedade. Assim, áreas como previdência, educação, preservação do meio ambiente, saúde e desenvolvimento urbano, são acompanhadas pelos devidos administrados que exercem controle e participação nas decisões referentes aos direitos humanos. 
A Constituição Federal de 1988 “(...) consagrou um novo princípio de organização da Administração Pública - o princípio da participação popular" (PEREZ, 2004: 85). Encontra-se assim esse princípio, de forma implícita, fragmentada em uma série de normas constitucionais (artigo 10, artigo 29, XII; artigo 37, §3으, dentre outros), bem como, derivada, posto que atrelada a outros princípios constitucionais, como o princípio do Estado de Direito, o princípio democrático e o princípio da eficiência administrativa e estruturante da atividade da Administração Pública. O autor afirma que, em primeiro lugar, no plano político:

A evolução da democracia, sua consagração pelo Direito Constitucional e, de certo modo, as dificuldades enfrentadas pelo modelo liberalrepresentativo produziram um terreno bastante fértil à proliferação da chamada democracia participativa. Esta, embora não simbolizasse o abandono dos institutos jurídicos da democracia representativa, importou na adoção de outros institutos jurídicos, voltados a tornar possivel o exercício ativo da cidadania, impondo a abertura da Administração Pública à participação dos cidadãos" (PEREZ, 2004: 203).

Segundo Bucci (2006), os institutos de participação popular na Administração Pública garantidos pela Constituição possibilitam que os administrados tenham acesso e atuem não só na direção e planejamento, como no controle e avaliação das políticas urbanas referentes a assuntos de interesse público, visando tornar as decisões administrativas mais eficientes nos aspectos sociais antes ignorados pelo administrador público, garantindo, assim, direitos fundamentais da população em processos decisórios. Para o autor, a noção de gestão democrática, trazida no capítulo IV do Estatuto da Cidade, é ponto crucial e substancial para os novos instrumentos de direito urbanístico ou, mais precisamente, de política urbana, objeto dos capítulos II ("Dos Instrumentos da Política Urbana") e III ("Do Plano Diretor") do Estatuto (2006: 336).

Assim, dispõe o Estatuto da Cidade que, para garantir a gestão democrática da cidade, deverão ser utilizados instrumentos, como os órgãos colegiados de política urbana, debates, audiências e consultas públicas, conferências sobre assuntos de interesse urbano, nos níveis nacional, estadual e municipal, e de iniciativa popular de projeto de lei e de planos, programas e projetos de desenvolvimento urbano, dentre outros (BRASIL, 2001).

Percebe-se, portanto, a participação da população em vários segmentos decisórios do desenvolvimento urbano, tais como na execução e no acompanhamento de planos, programas e projetos, com importante papel na consecução dos fins pretendidos pela gestão democrática da cidade.

A participação no exercício das funções estatais "populariza", se assim podemos dizer, o Direito, dessacralizando-o. O Direito desce do pedestal 
e passa, de fato, a ser comentado e interpretado em meio aos conflitos, divergências e disputas sociais. Desnudado e politizado, o Direito nada perde, mas, ao contrário, ganha nova força, fruto de sua adequação à realidade social. (PEREZ, 2004: 62).

Somente através da participação popular efetiva pode-se garantir que os instrumentos de política urbana do Estatuto da Cidade sejam efetivamente utilizados em prol do bem-estar coletivo, de modo que a população tenha acesso a uma política urbana justa e igualitária.

Marcelo Lopes de Souza (2016) disserta sobre o sistema técnico ser falho e defende a participação popular de maneira democrática como melhor alternativa para mudar a cidade:

(...) O papel dos intelectuais, pesquisadores, e técnicos versados ou interessados em teoria e técnicas do planejamento e gestão urbanos (...) é modesto, pois esta tarefa de transformar a realidade sócio-espacial, sendo essencialmente política, só pode ser, para ser autêntica e legítima, sob um ângulo autonomista, uma tarefa assumida material e intelectualmente por uma coletividade e conduzida democraticamente e não inspirada por intelectuais tecnocráticos e imposta pelo Estado. (SOUZA, 2016: 531).

Outrossim, Ermínia Maricato e João Sette Whitaker Ferreira (2002) seguem o mesmo pensamento crítico sobre o sistema tecnocrático imposto pelo Estado, senão vejamos:

O espaço urbano é uma construção social e a gestão do Poder Público não pode se restringir a uma normatização burocrática, pois nesse caso, sem dúvida a eficácia (tendo em vista o interesse público e social) ficará comprometida. Essa foi uma das grandes falhas do urbanismo funcionalista cuja operação foi excessivamente centralizada pelo Estado. (MARICATO; FERREIRA, 2002: 14)

Assim, os Municípios possuem não somente poderes para intervenção sobre processos de urbanização, mas obtém, através do Estatuto da Cidade, certo domínio sobre o mercado imobiliário, que se beneficia exacerbadamente da cidade. Entretanto, também de acordo com o Estatuto da Cidade, caberia ao próprio Poder Público reter privilégios do setor que ainda persistem.

Para Felipe Nunes Magalhães, João Bosco Moura Tonucci Filho e Harley Silva (2011), a valorização imobiliária poderia funcionar de uma forma benéfica para o planejamento urbano se os instrumentos do Estatuto da Cidade estivessem em pleno vigor:

Seja através da Outorga Onerosa do Direito de Construir aliada a parâmetros de Ocupação menos permissivos nas áreas mais valorizadas, ou de operações Urbanas que fossem efetivamente desenhadas com o intuito de distribuir os sublucros fundiários para a habitação social ou o provimento de infraestrutura básica em áreas vizinhas a estes projetos, dentre outras formas através das quais os instrumentos do Estatuto possibilitariam essa redistribuição dos benefícios da valorização imobiliária para a cidade como um todo, seguindo critérios de priorização democraticamente elencados. O parcelamento, edificação e utilização compulsórios de terrenos e imóveis vago, associados ao IPTU progressivo 
no tempo, contribuíram para combater a retenção especulativa do solo, além de garantir o aumento da oferta de unidades residenciais. Todavia, perde-se tal oportunidade, justo neste histórico momento de aumento exponencial da renda fundiária urbana na metrópole brasileira. (MAGALHÃES; TONUCCI FILHO; SILVA, 2011:31).

Importante salientar que a participação popular no Estado de Direito contemporâneo em outras funções estatais é de grande alcance, posto que tal atuação não se restringe somente à Administração Pública, mas também na atuação legislativa e na função jurisdicional, conforme disserta PEREZ (2004). Ainda segundo o autor, é perceptível a eficácia do entrosamento popular na Administração Pública, visto a importância da democracia participativa nos controles sobre a atuação estatal, fiscalizando e impedindo imprudências, de modo a obrigar o Estado a solidificar os direitos humanos, tornando-os objetivos primordiais e incontestáveis a serem alcançados.

A relação entre desenvolvimento urbano, participação da população e Administração Pública é ressaltada por Jane Jacobs (2000). Essa participação, para a autora, deveria ser uma ferramenta norteadora das propostas de transformação dos espaços das cidades e impeditiva do planejamento urbano moderno e destruidor da cidade tradicional proporcionado pela Administração Pública. A autora criticava os projetos institucionais que, em nome do progresso, destruíam os espaços públicos das cidades, desconsiderando as diferenças sociais e o cotidiano da população. Segundo Lefebvre, "ela mostrou, com muita força o poder destrutivo e a autodestruição da vida urbana pelos meios aparentemente destinados a criá-la ou recriá-la" (LEFEBVRE, 1991).

Jacobs (2000), após desenvolver toda uma crítica às experiências das práticas urbanas, indicou as condições básicas para se alcançar a propriedade indispensável a um espaço urbano, a diversidade. A primeira condição seria a necessidade de usos combinados, como o residencial e o comercial, distribuídos pelo espaço urbano. Outra condição seria a mobilização da população para se tornar o que denominou como os "olhos da rua [...], um tipo de vizinhança vigilante e participativa, envolvida com o espaço público" (JACOBS, 2000: 245). Para a autora, essa última condição contribuiria para a sociedade urbana, na medida em que as questões da cidade sairiam do domínio da tecnocracia.

\section{A OPERAÇÃO URBANA NOVA BH OU ANTÔNIO CARLOS/PEDRO I E LESTE/OESTE}

O projeto de lei Nova BH, assim nomeado inicialmente em 2013 pelo Poder Público Municipal, foi uma proposta de Operação Urbana Consorciada (OUC) para a capital mineira, 
envolvendo 58 bairros, divididos em 10 setores, abrangendo uma área de cerca de $25 \mathrm{~km}^{2}$ (9\% da extensão territorial da cidade), afetando aproximadamente 170 mil moradores (7\% da população de Belo Horizonte).

As principais áreas de impacto seriam os corredores das Avenidas Antônio Carlos/Pedro I, bem como, trechos das Avenidas Andradas, Tereza Cristina e Via Expressa, que pertencem à bacia do Ribeirão Arrudas. (PBH, 2015).

A ideia de utilização da OUC surgiu após a 3ạ Conferência de Política Urbana, realizada em 2009, na qual os técnicos da Prefeitura Municipal constataram a necessidade de investimento nas áreas acima mencionadas para melhorias, principalmente na mobilidade urbana, visto que a região passaria por intervenções em prol do transporte, como a implantação do BRT (transporte de ônibus rápido). Aproveitando-se das mudanças viárias que afetariam o espaço, outras medidas também precisariam ser aplicadas para recuperar os prejuízos aos agentes lesados, sendo estas divididas em três eixos: estrutural, socioambiental e econômico (FIG.1.).

Figura 1. Proposta da Operação Urbana Nova BH.

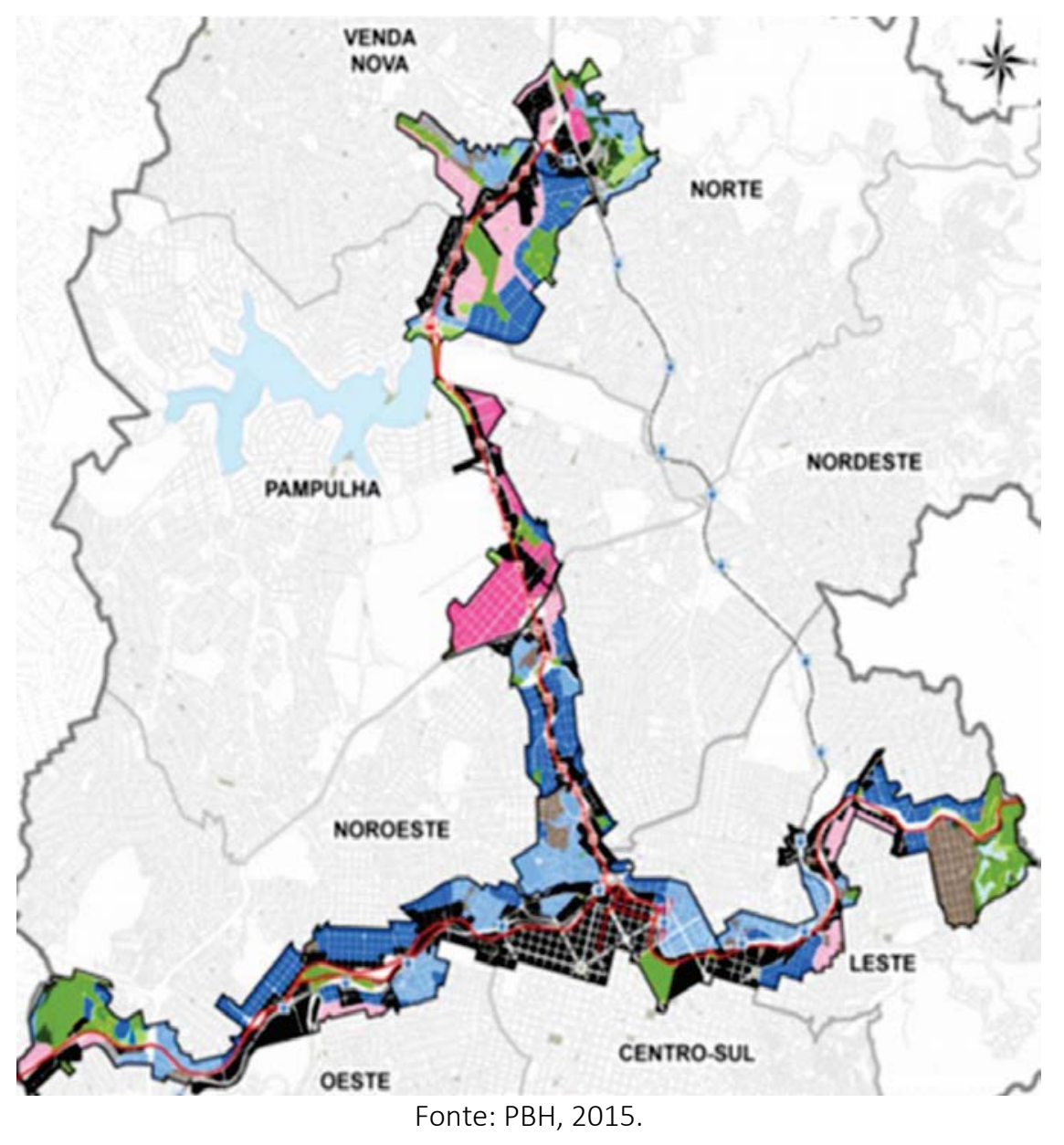


No eixo estrutural, previa-se que a Prefeitura direcionasse o crescimento da cidade próximo aos corredores de transporte coletivo, além de criar novos centros de trabalho e serviços, diminuindo-se, assim, o deslocamento de pessoas. No aspecto econômico, objetivouse a renovação das áreas próximas aos corredores coletivos, promovendo-as, e das empresas de setores estratégicos da economia da cidade. No quesito socioambiental, buscou-se a revitalização de vilas e aglomerados localizados dentro da área da operação.

O custo total do projeto estava estimado em 04 bilhões de reais, valor que seria arrecadado através da venda dos Certificados de Potencial Construtivo (CEPACs), que funcionariam como direitos concedidos pelo Município de Belo Horizonte para ampliação de construções (PBH, 2013). Tais certificados seriam convertidos em metragem quadrada de acordo com a localização do empreendimento: áreas mais valorizadas, o preço seria elevado, e áreas menos valorizadas, preços mais acessíveis (FIG. 2).

Figura 2. Proposta da Operação Urbana Nova BH.

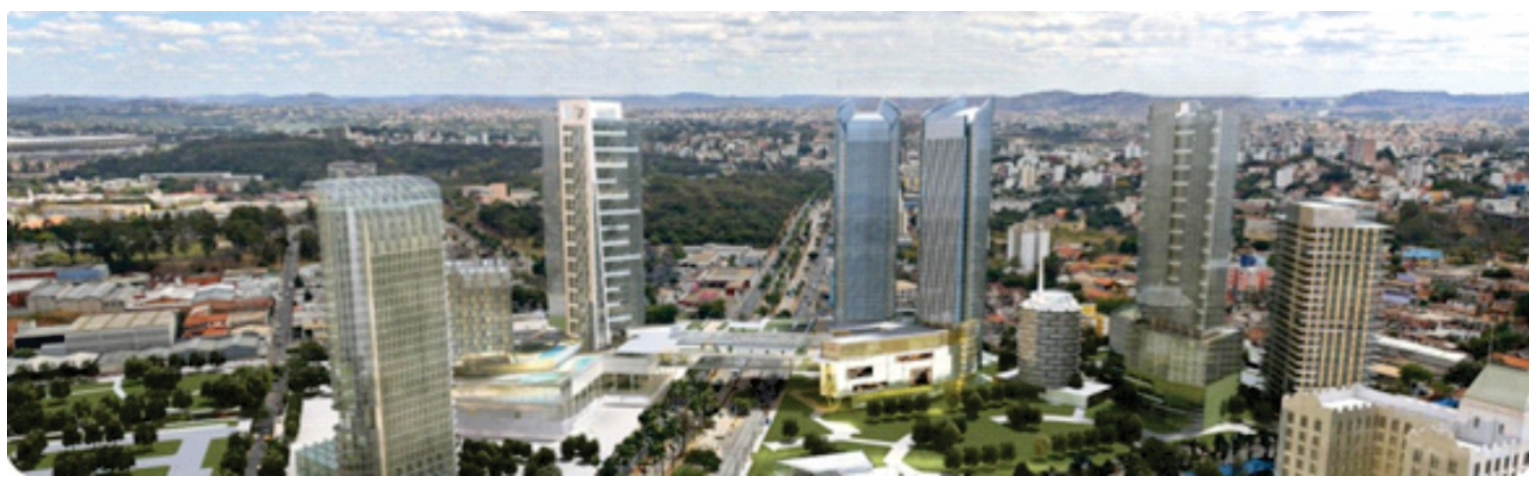

Fonte: PBH, 2015.

Muito embora a Operação Nova BH tenha sido de iniciativa do Município, referido projeto contou com a participação da iniciativa privada, através da Manifestação de Interesses da Iniciativa Privada (MIP). Lado outro, contudo, tal projeto foi desenvolvido sem a participação direta dos demais agentes envolvidos na Operação Urbana, quais sejam, moradores, comerciantes, trabalhadores, transeuntes e afins, o que gerou revolta por parte da população e de intelectuais envolvidos na causa em prol de melhorias no projeto com ênfase na problemática desapropriação dos imóveis. Em razão disso, o caso ganhou repercussão e foi denunciado no Ministério Público, que passou a averiguar irregularidades do projeto. (JORNAL O TEMPO, 2014) 
Ainda sobre protesto, a Prefeitura Municipal conseguiu aprovar o Estudo de Impacto de Vizinhança (EIV) pelo Conselho Municipal de Política Urbana (Compur ${ }^{2}$ ), formado, em sua maioria, por membros do próprio Poder Público e setores privados (PBH, 2015), exercendo forte influência nas decisões e inibindo a atuação popular representada por associações comunitárias e agentes do terceiro setor.

Cota (2011) acusa falhas no âmbito democrático, quanto ao Conselho Municipal de Política Urbana (COMPUR), o qual é composto em sua maioria por técnicos e representantes da iniciativa privada, inibindo a participação popular - minoria do conselho - por meio de melhor embasamento e domínio técnico, tornado o processo prejudicial democraticamente, pois:

(...) os avanços conquistados, especialmente no âmbito do planejamento, encontram-se limitados por certas permanências sociopolíticas (de gestão) que entram em choque com os ideais democráticos mais elementares, comprometendo a efetivação dos princípios do direito à cidade e da reforma urbana. (COTA, 2011:317).

Com o EIV aprovado, o projeto da Operação Urbana seria enviado em forma de minuta de lei para aprovação na Câmara dos Deputados; contudo, o Ministério Público de Minas Gerais (MPMG) interveio e paralisou a operação, alegando a gravidade da aceitação do Estudo de Impacto de Vizinhança previsto no Estatuto da Cidade sem promover amplo debate com a sociedade civil, o que violaria o princípio da gestão democrática da cidade, também previsto no Estatuto da Cidade (LARCHER, SOUZA, 2016).

De acordo com o Estatuto da Cidade (BRASIL, 2001), a população tem o direito garantido de participar diretamente do plano urbanístico da cidade. Essa participação se dá por meio de discussões e audiências públicas, onde serão analisadas a elaboração, a revisão e o acompanhamento da operação urbana consorciada.

\footnotetext{
${ }^{2}$ O Compur é uma instância de discussão e deliberação de políticas de planejamento urbano e gestão do território de Belo Horizonte instituída em 1996 pelo Plano Diretor do Município. O Compur agrega funções como acompanhar as ações de intervenção pública na estrutura urbana do município, manifestar-se sobre temas afetos à política urbana e propor intervenções e soluções a eles relacionadas, monitorar a implementação das normas contidas no Plano Diretor e na Lei de Parcelamento, Ocupação e Uso do Solo - LPOUS, decidir premissas para regulamentação de instrumentos de política urbana, deliberar sobre a instalação e funcionamento de empreendimentos de grande porte, por meio da avaliação de EIV. As reuniões do Conselho são abertas à comunidade, podendo a população acompanhar e manifestar (PBH, 2014). O Compur é composto por 16 membros. Oito são representantes da sociedade civil, escolhidos entre entidades ou cidadãos de destacada atuação na cidade, na área de arquitetura e urbanismo. Conta ainda com 7 representantes do Poder Público Municipal (incluindo o legislativo) e um pesquisador, cientista, tecnólogo ou pessoa de notório saber, de livre escolha do prefeito. Aspecto importante a ressaltar é que a presidência do conselho sempre fica a cargo do Secretário Municipal de Desenvolvimento Urbano, portanto, a direção é sempre do Poder Público, que possui, de acordo com o regimento interno, grandes poderes dentro do Compur (PBH, 2015).
} 
O Ministério Público de Minas Gerais (MPMG), através da Promotoria de Justiça de Habitação e Urbanismo de Belo Horizonte, em 25 de novembro de 2013, após a abertura do Inquérito Civil no 002413.009688-6, e, por meio da Recomendação no 008/2013, se insurgiu contra a implantação de OUC Nova BH, que tinha início das obras previsto para 2014 (FIG 3).

\section{Figura 3. Audiência do MPMG sobre a Proposta da Operação Urbana Nova BH.}

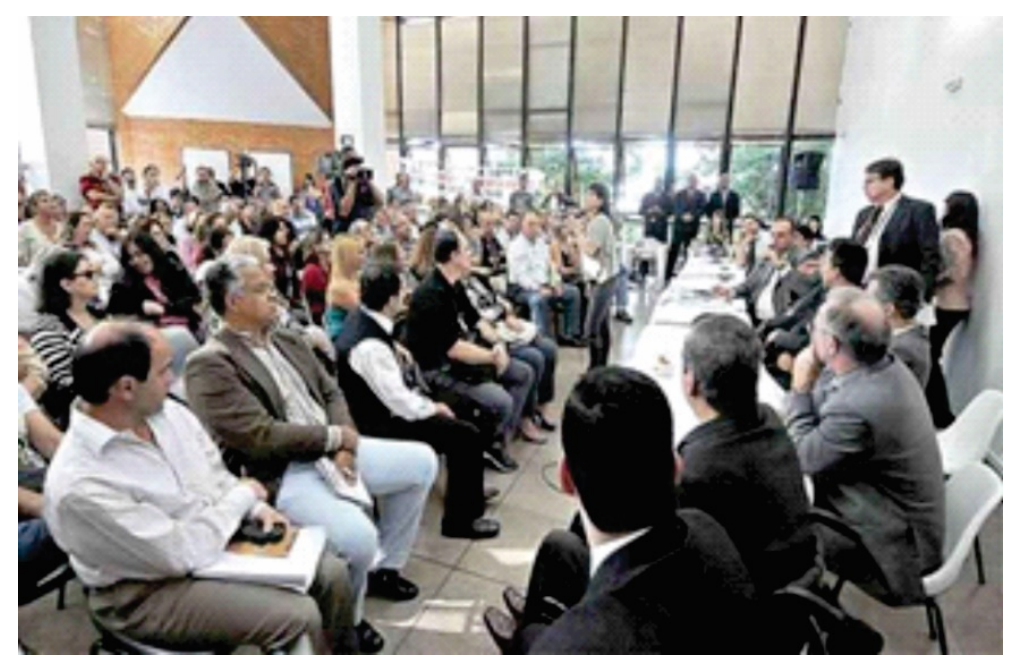

Fonte: PBH, 2015.

O MPMG considerou falho o processo de publicidade do EIV e de participação popular, posto que não ocorreram debates e audiências entre as partes envolvidas, com prévia e ampla publicidade dos estudos técnicos pertinentes, conforme previsto no Estatuto da Cidade. O MPMG relata que:

Tratando especificamente dos instrumentos da política urbana, entendese que a implantação da Operação Urbana Consorciada é um instrumento de participação, uma vez que deverá ser dada publicidade de seu teor e questionada pela população residente, podendo obstar a instalação de equipamentos que causem impacto negativo. Assim, restou demonstrado nos autos que tais previsões normativas, a princípio, não estão sendo integralmente cumpridas; isto é, a Municipalidade não ofertou a possibilidade de gestão participativa aos representantes da sociedade civil (população, bem como as associações representativas) sobre a Operação Urbana Consorciada [...]. (LARCHER, SOUZA, 2016).

O MPMG requereu que fosse dada ampla publicidade aos planos urbanísticos e ao EIV da Operação Urbana Nova BH, bem como, fossem promovidos debates com a sociedade, e recomendou aos Conselheiros do Conselho Municipal de Políticas Urbanas - COMPUR, que:

(...) se abstenha de encaminhar projeto de lei referente à Operação Urbana Consorciada à Câmara Municipal de Belo Horizonte, sem antes observar o que determina as Constituições Federal e Estadual, o Estatuto da Cidade, a Lei Orgânica do Município de Belo Horizonte e seu Plano 
Diretor, no que se refere à realização de debates e audiências, com prévia e ampla publicidade dos estudos técnicos pertinentes (LARCHER, SOUZA, 2016).

O Estatuto da Cidade (BRASIL, 2001) é expresso ao definir que o planejamento urbano das cidades tem que ser participativo, submetendo a vontade do Poder Público à dos demais agentes da produção do espaço. O artigo 33 do Estatuto da Cidade estabelece conteúdo mínimo para que a lei autorize a operação e, dentre eles e especialmente “(...) forma de controle da operação, obrigatoriamente compartilhado com representação da sociedade civil" (BRASIL, 2001). Por sua vez, o artigo 2으, incisos I e XII, do referido diploma legal, prevê uma "gestão democrática da cidade por meio da participação popular e de associações representativas" e "audiência do Poder Público Municipal e da população interessada (...)" (BRASIL, 2001).

Ainda com relação a essa participação, o geógrafo Marcelo Lopes de Souza (2014:33) afirma que:

(...) sob pena de inconstitucionalidade e ilegalidade da ação governamental, não há dúvida de que a participação da população e das associações representativas de vários segmentos da comunidade é norma geral da qual o administrador municipal não pode se esquivar na formulação, na execução e no acompanhamento de planos, projetos e programas de desenvolvimento urbano (...).

$\mathrm{Na}$ operação Nova BH, essa participação não aconteceu como previsto no Estatuto da Cidade. As decisões e os rumos do projeto estavam sendo pautados pelos funcionários da PBH e empresas de iniciativa privada, através da Manifestação de Interesse da Iniciativa Privada (MIP). Desta forma, os interesses diretos da população não estavam tendo espaço no projeto, em total desrespeito à gestão democrática, o que gerou grande indignação de pensadores, intelectuais e da população de forma geral.

O Compur, desta vez e de forma a cumprir seu papel de garantir a gestão democrática da cidade, realizou reuniões e audiências públicas abrindo espaço para a população defender seus interesses. Tais reuniões e audiências ocorreram entre os anos de 2010 e 2015 e, segundo estudos sobre a atuação do Compur para com a população, verifica-se que a participação popular se dava em pequena escala das reuniões, através de associações comunitárias e entidades do terceiro setor. Por outro lado, o setor empresarial possuía grande participação nas discussões.

A mobilização da população, juntamente com o apoio do Compur, conseguiu com que a PBH aprovasse em 2013, o Estudo de Impacto de Vizinhança. Segundo o Jornal "O Tempo" (2014), o projeto estava sendo encaminhado para a aprovação do Legislativo, quando a 
operação teve que ser paralisada, uma vez que a Prefeitura Municipal de Belo Horizonte reconheceu a pequena participação popular nas decisões até então tomadas. O Secretário Municipal de Planejamento Urbano cita que: "Agora queremos ouvir o morador de cada área que será afetada e mostrar que estamos sensibilizados com o posicionamento de cada um" (JORNAL O TEMPO, 2014).

Assim, depois das reivindicações da população e da Recomendação do MPMG, em 2013, a PBH paralisou o processo de implantação da NOVA BH (JORNAL O TEMPO, 2014). Posteriormente, no início de 2014, a PBH apresentou a Operação Urbana Consorciada Antônio Carlos/Pedro I e Leste/Oeste, recomeçando o processo de discussão. Segundo a PBH, trata-se de uma nova operação urbana (JORNAL O TEMPO, 2014).

A PBH, ciente de que a população deveria ter participação ativa em todos os processos de implantação da nova operação urbana, criou um cronograma de oficinas e audiências, onde os técnicos da Administração Municipal realizaram, em cada regional de Belo Horizonte, uma espécie de miniconferência de política urbana. Durante essas audiências, os técnicos destacaram pontos de mudança na Antônio Carlos/Pedro I e Leste/Oeste. Visitas ao local da intervenção, debates e audiências públicas foram realizadas para que as dúvidas fossem tiradas e ainda apresentadas opiniões dos cidadãos sobre o projeto. Todo o processo foi relatado e as audiências foram publicadas no site do Município de Belo Horizonte (PBH, 2015) (FIG. 4).

\section{Figura 4. Uma das diversas audiência do Compur sobre a Proposta da Operação Urbana Consorciada Antônio Carlos/Pedro I e Leste Oeste.}

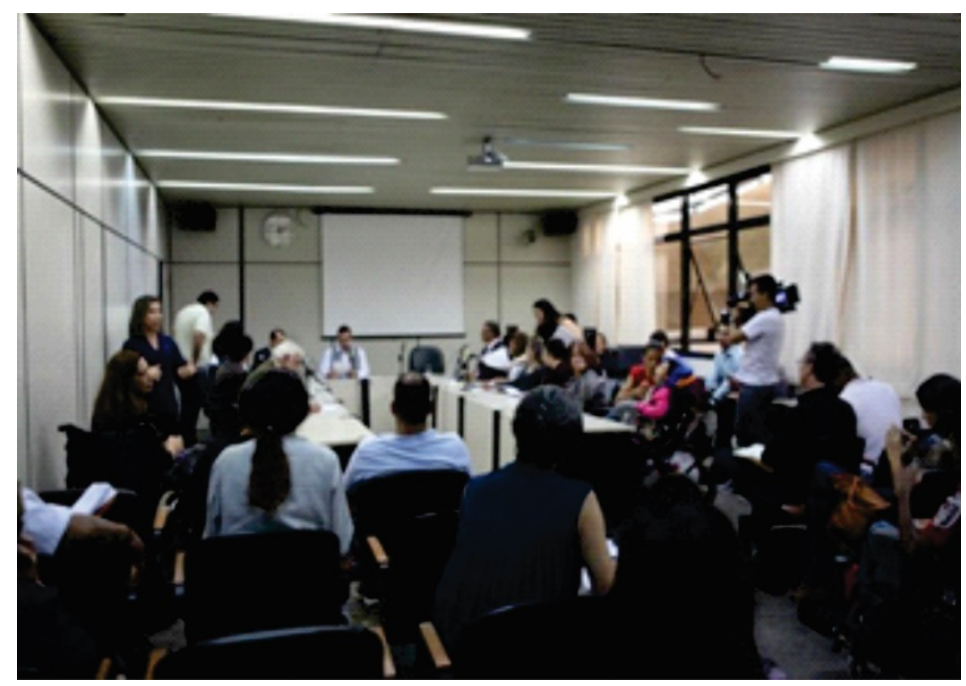

Fonte: PBH, 2015. 
Dentre as principais mudanças, destaca-se a inserção do Cemitério do Bonfim na proposta para receber obras com recursos oriundos da operação urbana, bem como a retirada do bairro São José, na Pampulha. Apenas quadras voltadas para a Avenida Antônio Carlos foram incluídas. Já os bairros Califórnia e Pindorama, na região Noroeste, passaram a fazer parte da Operação Urbana Consorciada, assim como, um trecho da Avenida Belém, no extremo Leste da capital (PBH, 2015).

Outra novidade da Operação Urbana Consorciada Antônio Carlos/Pedro I, Leste/Oeste e que não existia na Operação Urbana Consorciada Nova BH, é a maneira como seria formado o conselho de gestão dos recursos da operação urbana. Segundo a proposta da PBH, o conselho funcionaria com um detalhamento do projeto a longo prazo, garantindo que, com a divisão de tarefas por grupos de visões distintas, poderiam ser tomadas decisões mais positivas para todos os envolvidos. O órgão que decidiria os investimentos seria formado por 36 membros - $15 \mathrm{da}$ Prefeitura Municipal, 12 das associações de moradores, três de movimentos sociais e entidades técnicas, dois proprietários, dois comerciantes e dois investidores imobiliários. Esse grupo teria a função de definir as obras prioritárias, seguindo as diretrizes das intervenções já apontadas no plano inicial e o investimento destinado à habitação de interesse social (PBH, 2016).

Com a interrupção do projeto, a Prefeitura de Belo Horizonte deu um passo para trás e admitiu o erro na exclusão da participação democrática no projeto, o qual não foi enviado à Câmara dos Deputados (JORNAL O TEMPO, 2014) e passou por uma reformulação e reapresentação, seguindo as normas do Estatuto da Cidade (BRASIL, 2001).

Em meados de 2014, o projeto retornou como Operação Urbana Antônio Carlos/Pedro I e Leste/Oeste, reabrindo-se a discussão. De acordo com PBH, tratava-se de um novo projeto (PBH, 2014). A Operação Urbana retirava a participação massiva da iniciativa privada, possibilitando decisões mais democráticas.

A PBH utilizou-se, seguindo as diretrizes da Lei 10.257/2001, de ferramentas que garantiam a participação da população, criando uma espécie de miniconferências em cada regional de Belo Horizonte, com audiências e oficinas, além de debates e visitas locais. Tais medidas serviram para solucionar as complexidades do projeto, antes ignoradas pelo sistema tecnocrático, confirmando uma operação mais flexível e contextualizada.

As ações obtiveram fins notáveis em comparação à Nova BH, destacando-se: ampliação da abrangência da operação para 99 bairros, passando para $29 \mathrm{~km}^{2}$ a área do projeto, o que corresponde a $11 \%$ do território municipal; houve um redimensionamento do potencial da operação urbana, com a realização de menos construções de grande porte; e principalmente o 
incentivo da construção de habitações sociais, onde, no mínimo $20 \%$ de tudo que for arrecadado será destinado à habitação social. Para incentivar esse tipo de moradia, foram criados dois mecanismos: o aluguel social e a política de incentivos para apartamentos menores ao longo dos corredores. A previsão é a criação de 5.211 moradias sociais em 20 anos (AUDIÊNCIA, 2015).

Outros mecanismos ainda foram utilizados no quesito moradia, como o aluguel social, que proporciona valores proporcionais às moradias, evitando a especulação imobiliária e levando unidades habitacionais públicas para a região, promovendo a utilização da área pelas classes sociais; a tipologia incentivada (apartamentos de cerca de $50 \mathrm{~m}^{2}$, com um banheiro e, no máximo, uma vaga de garagem). Parte do estoque disponível é destinada à tipologia incentivada e a outra a tipologias livres.

A Operação Urbana Antônio Carlos/Pedro I e Leste/Oeste está baseada nas diretrizes da proposta de um novo Plano Diretor que surgiu a partir da 4a Conferência de Política Urbana. Em 2015, virou projeto de lei e foi encaminhado para a Câmara dos Vereadores, onde até então aguarda sua votação, que será de extrema importância para a Operação Urbana, pois, mesmo com o envio do projeto de lei da Operação Urbana para a Câmara de Vereadores, esta somente poderá ser votada após a aprovação do referido Plano.

\section{CONSIDERAÇÕES FINAIS}

O instrumento urbanístico e jurídico da Operação Urbana Consorciada em Belo Horizonte se depara com um paradoxo, no qual, na intenção de beneficiar a parte social, acaba por atuar como defensora exclusivamente do setor imobiliário. O Poder Público acaba por beneficiar os parceiros particulares, que buscam o ente público na tentativa de viabilizar seus projetos; por outro lado, o Estado, visando a contrapartida oferecida pelo setor privado, acaba deliberando a execução de políticas urbanas em espaços inconstitucionalmente definidos.

Baseado no estudo realizado acerca da Operação Urbana Nova BH, verifica-se que, na verdade, muito embora tenha se dado nova roupagem ao transformá-la em Operação Urbana Consorciada Antônio Carlos/Pedro I, Leste/Oeste, são visíveis as deficiências da Administração Pública na gerência e no atendimento à gestão democrática. Isso porque as tentativas de implementar a participação popular não foram eficazes, posto que efetivar a gestão não restringe a realizar audiências públicas, nas quais os cidadãos presentes têm participação apenas como ouvintes e espectadores. A gestão democrática não se concretiza apenas com a 
divulgação das datas das audiências em locais públicos e a entrega de panfletos à população, mas sim, com a construção conjunta das propostas por todos os agentes envolvidos na operação urbana consorciada.

Nota-se que o Poder Público Municipal foi ineficaz ao afirmar que utilizando o dinheiro da iniciativa privada nas obras de melhorias urbanas, aliviaria o peso sobre o Estado e beneficiaria, não apenas o setor imobiliário, mas também as camadas desprivilegiadas da cidade de Belo Horizonte.

Impende ressaltar que o Município é o ente federativo através do qual a atividade urbanística se manifesta de forma mais concreta e dinâmica, exercendo tal ente, portanto, função balizadora e primordial na consecução do atendimento aos princípios e diretrizes de desenvolvimento urbano, tais como a gestão democrática. Caso contrário, poder-se-á constatar, na prática, favorecimentos ao mercado imobiliário oportunizados pelo próprio Município, sendo que o papel de coibir tais privilégios pertence ao próprio ente público.

Pode-se afirmar, inclusive, que, somente com a observância da gestão democrática, assim entendida como a participação ativa e real dos cidadãos em debates e tomada de decisões acerca de planos, programas e projetos urbanísticos, será possível realizar uma organização e adequação do espaço urbano de forma justa, capaz de propiciar a todo cidadão um desenvolvimento equilibrado e saudável.

Outrossim, há que se ressaltar que o Poder Público Municipal tem o dever, posto que há previsão constitucional para tanto, de estabelecer os objetivos e as estratégias definidoras do processo de utilização do solo urbano.

Destaca-se, ainda, o fundamental papel fiscalizador exercido pelo Ministério Público Estadual na implementação das normas, posto que cabe ao Parquet a defesa da ordem jurídica, do regime democrático e dos interesses sociais e individuais disponíveis, de modo a assegurar a plena realização da gestão democrática. Ressalta-se, sobremaneira, que o papel de fiscalizador é imprescindível, uma vez que o Ministério Público é uma instituição sem qualquer vinculação política ou partidária com a gestão executiva, o que gera credibilidade e traz confiança para a população. A sua atuação possibilitou que o processo da Operação Urbana Nova BH fosse paralisado frente ao não atendimento às diretrizes explicitadas pelo Estatuto da Cidade com relação à gestão democrática da cidade. Posteriormente, o Poder Público Municipal, iniciou novo processo, permitindo desta vez uma maior participação popular e não apenas de alguns segmentos da sociedade. 
Assim, para se garantir o mínimo de igualdade à sociedade, faz-se necessária a participação popular nas decisões afetas ao interesse público, a fim de se garantir o controle e a avaliação das políticas urbanas referentes a assuntos de interesse da sociedade, no que se refere ao aspecto social das decisões.

Enfim, o processo de gestão democrática é entendido como maneira de planejar, produzir, operar e governar cidades submetidas ao controle e à participação social. Porém, ele só será possível mediante a articulação entre Poder Público e cidadãos, cumprindo com os mecanismos do Estatuto da Cidade, em busca de cidades mais sustentáveis, tendo como centro a qualidade de vida da pessoa humana. Restringir a participação do povo nos processos decisórios que digam respeito ao seu Município é recusar sua cidadania e, além disso, uma afronta aos princípios constitucionais fundamentais.

\section{REFERÊNCIAS BIBLIOGRÁFICAS}

BRASIL. Constituição (1988). Emenda Constitucional no 19, de 04 de Junho de 1998. Modifica o regime e dispõe sobre princípios e normas da Administração Pública, servidores e agentes políticos, controle de despesas e finanças públicas e custeio de atividades a cargo do Distrito Federal, e dá outras providências. In: CONSTITUIÇÃO DA REPÚBLICA FEDERATIVA DO BRASIL. Brasília, DF: Senado Federal: Centro Gráfico, 1988.

Estatuto da Cidade: guia para implementação pelos municípios e cidadãos: Lei n.10.257, de 10/07/2001, que estabelece diretrizes gerais da política urbana. Brasília: Câmara dos Deputados, Coordenação de Publicações, 2001.

BUCCI, Maria Paula Dallari. Gestão Democrática da Cidade in DALLARI, Adilson Abreu; FERRAZ, Sérgio. Estatuto da Cidade: Comentários à Lei Federal 10.257/2001. São Paulo: Malheiros, 2006.

COTA, Daniela Abritta. Descompassos entre o discurso e a prática das Operações Urbanas em Belo Horizonte (1997-2008). In: MENDONÇA, Jupira Gomes de; COSTA, Heloisa Soares de Moura. (Org.). Estado e capital imobiliário: convergências atuais na produção do espaço urbano brasileiro. 19.ed.Belo Horizonte: C/Arte, 2012, v., p. 301-321.

FERNANDES, Edésio, organizador. Direito Urbanístico. Belo Horizonte: Del Rey Editora, 1998.

FERREIRA, Ximena Cardozo Ferreira. A Atuação do Ministério Público na implementação de políticas públicas na área ambiental, Disponível: www.mppi.mp.br/internet/phocadownload/artigos/579.doc. Acessado em 30.01.2017.

FIX, Mariana. Parceiros da Exclusão: duas histórias da construção de uma "nova cidade" em São Paulo: Faria Lima e Agua Espraiada. São Paulo: Boitempo. 2001.

JACOBS, Jane. Morte e vida de grandes cidades. São Paulo: Martins Fontes, 2000.

LEFEBVRE, H. The production of space. Oxford, OX, UK; Cambridge, Blackwell, 1991. 
LOMAR, Paulo José Villela. Operação Urbana Consorciada. In Estatuto da Cidade (Comentários à Lei Federal 10.257/2001), organizada por Adilson Abreu Dallari e Sérgio Ferraz. 2 ed. São Paulo: Malheiros Editores, 2001.

MAGALHÃES, Felipe Nunes; TONUCCI FILHO, João Bosco Moura; Silva, Harley. Valorização imobiliária e produção do espaço: novas frentes na RMBH. in Estado e capital imobiliário: convergências atuais na produção do espaço urbano brasileiro. 1ạ.ed.Belo Horizonte: C/Arte, 2012, v., p. 301-321.

MARICATO, Ermínia; WHITAKER, João Sette. Operação urbana consorciada: diversificação urbanística participativa ou aprofundamento da desigualdade? Texto. 2002. Disponível em: http://cidadesparaquem.org/textos-acadmicos/2002/7/1/operao-urbana-consorciadadiversificao-urbanstica-participativa-ou-aprofundamento-da-desigualdade. Consultado em 21 de Fevereiro de 2017.

O TEMPO, 2014. Jornal o Tempo. Operação Urbana Antônio Carlos/Nova BH Disponível em: http://www.otempo.com.br/cidades/nova-bh-volta-\%C3\%A0-estaca-zero-1.943079. Consultado em 01 de março de 2014.

(2015) Entenda a OUC ACLO. Disponível em: http://www.otempo.com.br/infogr\%C3\%A1ficos/entenda-a-ouc-aclo-1.1115213 Consultado em 15 de Setembro de 2016.

PBH. Prefeitura de Belo Horizonte. Audiência Pública sobre a Operação Urbana Nova BH. Disponível

em: http://portalpbh.pbh.gov.br/pbh/ecp/comunidade.do?evento=portlet\&pldPlc=ecpTaxonomiaM enuPortal\&app=pbh\&tax=53757\&lang=pt_. Consultado em 01 de nov. de 2015.

Cartilha

Nova

$\mathrm{BH}$.

Disponível

em:

http://portalpbh.pbh.gov.br/pbh/ecp/noticia.do?evento=portlet\&pAc=not\&idConteudo=12977 9\&pldPIc=\&app=salanoticias . Consultado em 25 de Outubro de 2013.

Cartilha

OUC

ACLO.

Disponível

em: http://portalpbh.pbh.gov.br/pbh/ecp/contents.do?evento=conteudo\&idConteudo=176095\&ch $\mathrm{Plc}=176095 \& \& p|d P| c=\& a p p=$ salanoticias . Consultado em 17 de Setembro de 2015.

Estrutura do Conselho - COMPUR. Disponível em:

http://portalpbh.pbh.gov.br/pbh/ecp/comunidade.do?evento=portlet\&pldPIc=ecpTaxonomiaM enuPortal\&app=planejamentourbano\&tax $=39582 \&$ lang $=p t \_b r \& p g=8843 \& \operatorname{taxp}=0 \&$. Consultado em 01 de Novembro de 2015.

Operação Urbana da Avenida Antônio Carlos. Disponível em: http://portalpbh.pbh.gov.br/pbh/ecp/comunidade.do?evento=portlet\&pldPIc=ecpTaxonomiaM enuPortal\&app=planejamentourbano\&tax $=39582 \&$ lang $=p t \_b r \& p g=8843 \& \operatorname{taxp}=0 \&$. Consultado em 20 de Setembro de 2016.

PEREZ, Marcos Augusto. A administração Pública Democrática: Institutos de Participação Popular na Administração Pública. Belo Horizonte: Fórum, 2004.

SARNO, Daniela Campos Liborio Di. Estatuto da Cidade (Comentários à Lei Federal 10.257/2001), organizada por Adilson Abreu Dallari e Sérgio Ferraz. 2 ed. São Paulo: Malheiros Editores, 2001.

SILVA, José Afonso da. Direito Urbanístico Brasileiro. São Paulo: Malheiros Editores, 2000. 
SOUZA, Marcelo Lopes de. Mudar a Cidade: Uma introdução crítica ao planejamento e à gestão urbana. São Paulo: Bertrand Brasil. 2016.

Trabalho enviado em 23 de março de 2017. Aceito em 09 de maio de 2017. 